\title{
Revisão do gênero Sympleurotis Bates (Coleoptera, Cerambycidae, Lamiinae, Colobotheini)
}

\author{
Carlos Eduardo de Alvarenga Julio ${ }^{1,2}$ \& Miguel A. Monné 1,3
}

\begin{abstract}
${ }^{1}$ Departamento de Entomologia, Museu Nacional, Universidade Federal do Rio Janeiro, Quinta da Boa Vista, São Cristóvão, 20940-040 Rio de Janeiro-RJ, Brasil.

${ }^{2}$ Bolsista de Pós-Doutorado CNPq (Proc. 150583/2003-6).

${ }^{3}$ Pesquisador do CNPq.
\end{abstract}

\begin{abstract}
Revision of the genus Sympleurotis Bates (Coleoptera, Cerambycidae, Lamiinae, Colobotheini). Sympleurotis Bates, 1881 is revised. Sympleurotis rudis Bates, 1881 and S. armatus Gahan, 1892 are redescribed and two new species added: $S$. wappesi sp. nov., from Guatemala and $S$. albofasciatus sp. nov., from Mexico. All the species are illustrated and keyed.
\end{abstract}

KEYWORDS. Cerambycidae, Colobotheini, new species, Sympleurotis, taxonomy

RESUMO. Revisão do gênero Sympleurotis Bates (Coleoptera, Cerambycidae, Lamiinae, Colobotheini). Sympleurotis Bates, 1881 é revisto. Sympleurotis rudis Bates, 1881 e S. armatus Gahan, 1892 são redescritos e acrescentam-se duas espécies novas: $S$. wappesi sp. nov., da Guatemala e S. albofasciatus sp. nov., do México. São fornecidas ilustrações e chave de identificação para as espécies.

PALAVRAS-CHAVE. Cerambycidae, Colobotheini, espécies novas, taxonomia.

Bates (1881) erigiu o gênero Sympleurotis para S. rudis procedente da Guatemala. Gahan (1892) descreveu S. armatus do México e Guatemala. O exame do material depositado nas coleções do Museu Nacional, Universidade Federal do Rio de Janeiro (MNRJ); National Museum of Natural History, Washington (USNM) e J. E. Wappes (JEWC) permitiu a descrição de duas espécies novas do México e Guatemala.

\section{Sympleurotis Bates, 1881}

Sympleurotis Bates, 1881: 185; Monné, 1995: 5 (cat.)

Espécie-tipo, Sympleurotis rudis Bates, 1881 (monotipia)

Redescrição. Corpo recoberto por pubescência decumbente, mais densa na superfície ventral. Cabeça lisa; fronte plana, com a margem inferior reta em ambos os sexos. Lobos oculares inferiores com o comprimento menor que o das genas (exceto em S. albofasciatus sp. nov., tão longo quanto as genas); lobos oculares superiores tão distantes entre si quanto o dobro da largura de um lobo (exceto em $S$. albofasciatus sp. nov., tão distantes quanto a largura de um lobo). Tubérculos anteníferos discretamente projetados. Antenas mais longas que o corpo tanto nos machos como nas fêmeas, com setas curtas, eretas e esparsas na face ventral do escapo, pedicelo e antenômero III; escapo subcilíndrico, não atinge a margem posterior do protórax; demais antenômeros cilíndricos; antenômero III o mais longo.

Protórax mais largo que longo; margens anterior e posterior pontuadas; lados subplanos, sem tubérculos; pronoto com tubérculos manifestos. Processo prosternal com 1/3 do diâmetro da cavidade procoxal; processo mesosternal plano, em declive anteriormente, com a mesma largura da cavidade mesocoxal e com pequeno entalhe no centro da margem posterior. Escutelo triangular. Élitros alongados, ligeiramente convexos, com suave decaimento posterior e comprimidos lateralmente; úmeros projetados; ápices elitrais truncados, o ângulo externo com projeção espiniforme aguda, mais longa nos machos e ângulo sutural não projetado; carena longitudinal lateral manifesta na metade basal, a partir dos úmeros; disco densamente pontuado, com pontos pilíferos esparsos e tubérculo centro-basal manifesto, mais ou menos projetado. Fêmures pedunculados e clavados; profêmures com pedúnculo curto. Metatarsômero I tão ou mais longo que os seguintes reunidos.

Segmento abdominal V, dos machos, moderadamente projetado além das extremidades elitrais; urotergito mais ou menos emarginado com os ângulos projetados; urosternito semicircularmente emarginado com os ângulos obtusos. Ovipositor acentuadamente projetado além das extremidades elitrais; urotergito aguçado e urosternito mais ou menos emarginado e com cerdas apicais longas.

Discussão: Sympleurotis pode ser diferenciado de outros gêneros da tribo pelo protórax inerme nos lados; pela presença de tubérculo centro-basal nos élitros e pelo segmento abdominal $\mathrm{V}$, das fêmeas, projetado para formar um longo ovipositor. 
Chave para as espécies de Sympleurotis

1. Lobos oculares inferiores com, aproximadamente, o mesmo comprimento das genas; lobos oculares superiores tão distantes entre si quanto a largura de um lobo; metatarsômero I mais longo que os seguintes reunidos; placa ventral do ovipositor com recorte estreito e profundo em forma de U alongado. México (fig. 4) S. albofasciatus sp. nov.

Lobos oculares inferiores com o comprimento menor que o das genas; lobos oculares superiores tão distantes entre si quanto o dobro da largura de um lobo; metarsômero I, no máximo, tão longo quanto os seguintes reunidos; placa ventral do ovipositor com outro formato

2(1). Pronoto com quatro tubérculos rombos, os dois anteriores mais desenvolvidos, centrais e próximos entre si e os dois posteriores laterais e afastados; pequena carena longitudinal centro-basal manifesta entre os dois tubérculos posteriores do pronoto; carenas laterais dos élitros projetadas. Guatemala (fig. 3) S. wappesi sp. nov.

Pronoto com dois tubérculos látero-anteriores discretamente elevados; carena longitudinal centrobasal no pronoto ausente; carenas elitrais laterais discretas

3(2). Antenas, nas fêmeas, longas, ultrapassam os ápices elitrais a partir da base do antenômero VII; lados do protórax, próximo à margem posterior, com pequeno espinho, pouco nítido, mais visível nas fêmeas; placa ventral do ovipositor com recorte raso em forma de U; segmento abdominal V, dos machos, projetado cerca de 1,0 $\mathrm{mm}$ além das extremidades elitrais. México e Guatemala (fig. 2) S. armatus Gahan, 1892

Antenas, nas fêmeas, mais curtas, ultrapassam os ápices elitrais a partir da base do antenômero IX; lados do protórax desarmados; placa ventral do ovipositor com recorte ligeiramente profundo em forma de $\mathrm{V}$; segmento abdominal $\mathrm{V}$, dos machos, discretamente projetado além das extremidades elitrais. México, Guatemala, Honduras e Panamá (fig.1)

S. rudis Bates, 1881

\section{Sympleurotis rudis Bates, 1881}

(Fig. 1)

Sympleurotis rudis Bates, 1881: 185; Lameere, 1883: 71 (cat.); Chemsak \& Linsley, 1970: 416 (lect.); Chemsak et al., 1992: 151 (cat.); Monné, 1995: 5 (cat.); Noguera \& Chemsak, 1996: 407 (cat.).

Redescrição. Macho. Tegumento castanho-avermelhado. Pubescência decumbente castanho-escura, cinérea e alaranjada, mescladas, revestem a superfície dorsal da cabeça, o protórax e os élitros. Pubescência decumbente esbranquiçada reveste: o escapo, mais densamente na superfície ventral e formando anel mediano; a base dos antenômeros III-XI; os fêmures, exceto área anelar mediana; as tíbias, exceto nas superfícies dorsais basal e apical; a metade basal dos tarsômeros I; e densamente a superfície ventral do corpo.

Antenas alcançam os ápices elitrais na metade do antenômero VI; escapo com, aproximadamente, o mesmo comprimento do antenômero IV; antenômeros III - XI gradualmente decrescentes em comprimento.

Protórax com pontuação mais aparente junto à margem posterior. Pronoto com dois tubérculos rombos, láteroanteriores, manifestos, duas faixas laterais longitudinais de pubescência aveludada castanho-escura com estreitamento mediano e que não atingem as margens anterior e posterior e uma pequena linha longitudinal centro-basal castanho-escura. Escutelo com triângulo central de pubescência esbranquiçada. Élitros com pontos de pubescência castanho-escura ao longo das margens suturais; pequena mancha aveludada transversal de pubescência castanho-escura próxima ao início da declividade posterior, mais densa próxima à sutura, margeada anteriormente por pubescência esbranquiçada; tubérculo centro-basal manifesto com pontos pilíferos no topo; ápices truncados, com projeção externa espiniforme. Meso- e metatarsômeros I longos, o comprimento do mesotarsômero I é igual ao dos dois seguintes reunidos e do metatarsômero I é subigual ao dos seguintes reunidos.

Segmento abdominal V discretamente projetado além dos ápices elitrais; urotergito com recorte semicircular e ângulos projetados e agudos; urosternito com emarginação semicircular e ângulos arredondados.

Fêmea. Antenas ultrapassam os ápices elitrais a partir da base do antenômero IX; ápices elitrais com ângulo externo pouco projetado. Ovipositor projetado cerca de $5,0 \mathrm{~mm}$ além das extremidades elitrais; urotergito aguçado; ursternito com recorte ligeiramente profundo em forma de $\mathrm{V}$.

Dimensões $(\mathrm{mm})$, respectivamente macho e fêmea: comprimento total, $11,5-8,6$ e 12,8-12,0; comprimento do protórax, 2,2-1,5 e 2,2-2,0; maior largura do protórax, 3,0-2,1 e 3,0-2,8; comprimento do élitro, 8,7-6,4 e 9,5-9,2; largura umeral, $4,3-3,1$ e $4,5-4,3$.

Material examinado. MÉXICO. Colina: El Terrero, fêmea, IX.1991, J.E.Wappes; Jalisco: 12 km N ElTuito, macho, VII.1990, J.E.Wappes; GUATEMALA. Zacapa: Sieira de las Minas (San Lorenzo Rd, $20.5 \mathrm{~km}$ N of Hwy. 9, ca. 1700 m), macho e fêmea, VI.1993, W.B.Warnes; San Lorenzo, macho, VI.1991, J.W.Wappes; 9 km S San Jeronimo, macho, VI.1966, J.M.Campbell; HONDURAS. Paraiso: Cerro Monserrat, 7 km SW Yuscarán, 1800, macho, V.1994; PANAMÁ. Chiriqui: 7 km SE Fortuna Dam, 1200 m, macho, V.1993, A. Gillogly. Todos na coleção J. E. Wappes. 
Sympleurotis armatus Gahan, 1892

(Fig. 2)
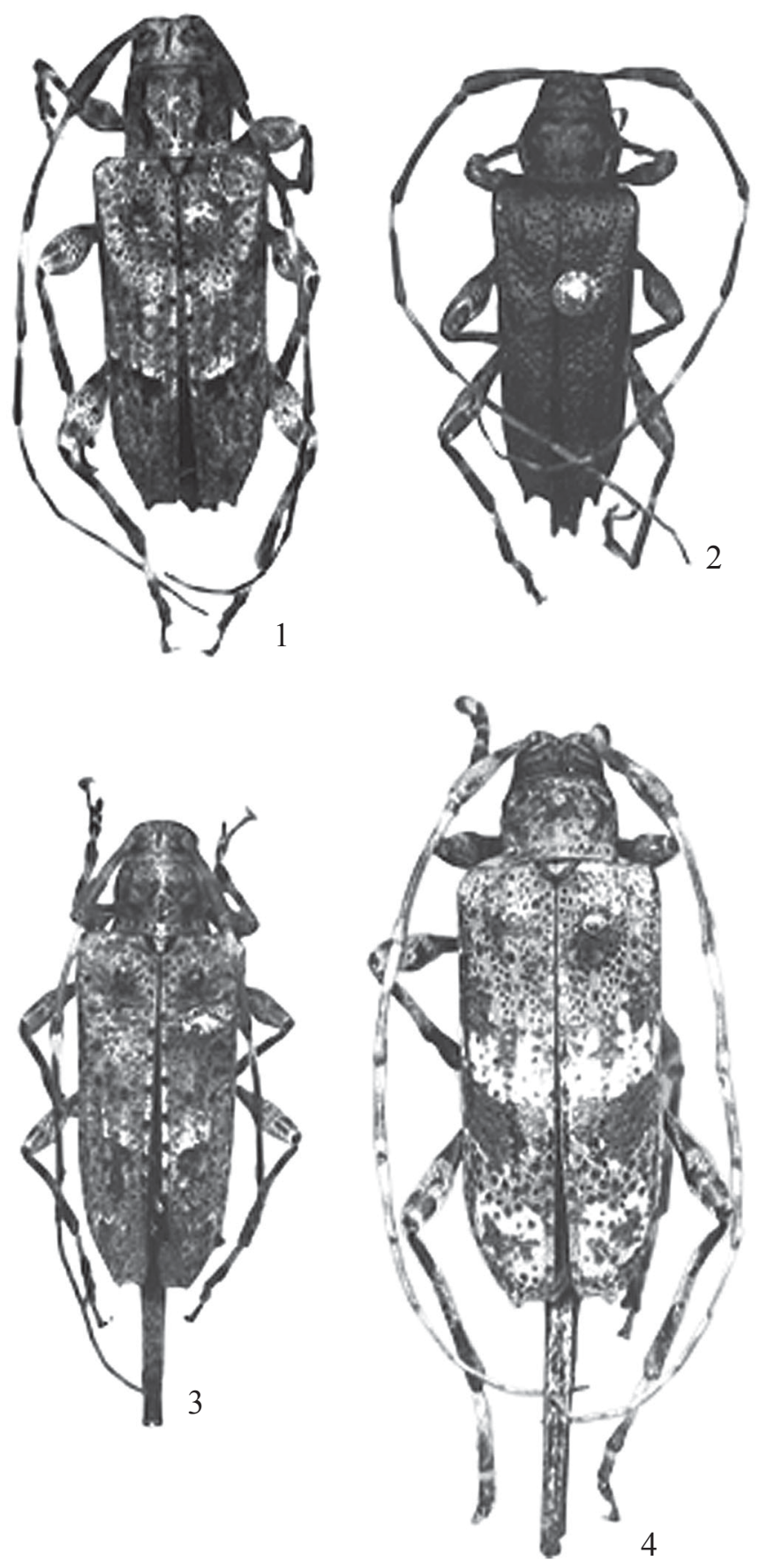

Figs. 1-4. 1, Sympleurotis rudis Bates, 1881, macho (coleção J. E. Wappes), Sieira de las Minas (San Lorenzo Rd, $20.5 \mathrm{~km} \mathrm{~N}$ of Hwy. 9, ca. $1700 \mathrm{~m}$ ), Zacapa, Guatemala, comprimento $11,5 \mathrm{~mm}$; 2. S. armatus Gahan, 1892, macho (MNRJ), 18-23 km S Filo de Caballo, Guerrero, México, comprimento 8,6 mm; 3. S. wappesi sp. nov., holótipo fêmea (USNM), 28-29 km N Sn Augustin, El Progreso, Guatemala, comprimento $11,0 \mathrm{~mm}$; 4. S. albofasciatus $\mathbf{s p}$. nov., holótipo fêmea (MNRJ), Hwy. 131, $178 \mathrm{~km} \mathrm{~S}$ Oaxaca, México comprimento, 13,7 mm.
Sympleurotis armatus Gahan, 1892: 266, pl. 12, fig. 10; Chemsak et al., 1992: 151 (cat.); Monné, 1995: 5 (cat.); Noguera \& Chemsak, 1996: 407 (cat.).

Redescrição. Macho. Tegumento castanho-escuro nos élitros e castanho-avermelhado no restante do corpo. Pubescência decumbente cinérea e duas pequenas manchas transversais laterais, castanho-escuras, recobrem a metade apical dos élitros, não alcançando as margens suturais. Pubescência decumbente esbranquiçada densa, reveste: a superfície ventral do corpo; os lados da cabeça; a base dos tarsômeros I e II; as áreas basal e média dos fêmures; a superfície ventral das tíbias, onde forma, também, um anel mediano; e forma, nos élitros, uma pequena mancha transversal que não alcança a margem sutural e margeia, inferiormente, a mancha lateral castanho-escura.

Antenas ultrapassam os ápices elitrais por, aproximadamente, cinco antenômeros; escapo com, aproximadamente, o mesmo comprimento do antenômero IV; antenômeros III-XI gradualmente decrescentes em comprimento, com pubescência decumbente esbranquiçada ao redor da base.

Protórax com pontuação profunda mais evidente na margem posterior; pronoto com tubérculos látero-anteriores rombos e discretamente elevados; os lados, próximo à margem posterior, com pequeno espinho pouco nítido, mais visível nas fêmeas; pequena faixa transversal de pubescência decumbente esbranquiçada presente acima de cada espinho. Escutelo preto, com pequena pubescência esbranquiçada triangular. Élitros com pontuação profunda mais densa na metade basal; região centro-basal ligeiramente elevada; ápices truncados com projeção externa espiniforme longa e bastante afilada. Meso- e metafêmures com o pedúnculo longo e a clava pouco robusta. Metatarsômero I tão longo quanto os seguintes reunidos.

Segmento abdominal V projetado cerca de $1,0 \mathrm{~mm}$ além das extremidades elitrais; urotergito com profundo recorte semicircular e ângulos acentuadamente projetados e afilados.

Fêmea. Antenas ultrapassam os ápices elitrais a partir da base do antenômero VIII; espinhos protorácicos láteroposteriores mais visíveis que nos machos; extremidades elitrais com ângulo externo pouco projetado. Ovipositor projetado cerca de 3,0 $\mathrm{mm}$ além das extremidades elitrais; urosternito com recorte raso em forma de $\mathrm{U}$; urotergito com o ápice bastante afilado.

Dimensões $(\mathrm{mm})$, respectivamente macho e fêmea: comprimento total, 8,6 e 8,6; comprimento do protórax, 1,6 e 1,5; maior largura do protórax, 2,3 e 2,1; comprimento do élitro, 6,5 e 6,5 ; largura umeral, 3,2 e 3,0 . 
Material examinado. MÉXICO. Oaxaca: Hwy. 131, $115 \mathrm{mi} \mathrm{S}$ Oaxaca, fêmea, V.1971, D.E.Bright; Guerrero: 18-23 km S Filo de Caballo, macho, IX.1989, J.E.Wappes. Ambos no MNRJ.

\section{Sympleurotis wappesi $\mathbf{s p . ~ n o v . ~}$}

(Fig. 3)

Descrição. Fêmea. Tegumento predominantemente castanho-escuro. Pubescência decumbente esbranquiçada reveste a cabeça, a metade basal do escapo, a base dos antenômeros III-VI, os fêmures, as tíbias, a metade basal dos tarsômeros I e a superfície ventral do corpo. Protórax e élitros recobertos por pubescência cinérea e manchas de pubescência amarelada mescladas.

Antenas ultrapassam os ápices elitrais a partir da base do antenômero IX; escapo com, aproximadamente, o mesmo comprimento do antenômero III; antenômeros III-XI gradualmente decrescentes em comprimento.

Margens anterior e posterior do protórax com pontuação profunda, os pontos da margem posterior com o diâmetro maior que os da anterior. Pronoto com quatro tubérculos rombos, os dois anteriores mais desenvolvidos, centrais e próximos entre si e os dois posteriores, laterais e afastados; pequena carena longitudinal centro-basal manifesta entre os dois tubérculos posteriores. Escutelo com um triângulo central de pubescência esbranquiçada. Élitros com tubérculo centro-basal protuberante, um pouco alongados longitudinalmente, granulados e com pontos pilíferos no topo; pontos de pubescência castanho-escura ao longo das margens suturais; pontuação profunda mais concentrada no terço basal; carenas laterais projetadas; ápices truncados com projeção externa pouco desenvolvida; mesotarsômero I com o mesmo comprimento dos dois seguintes reunidos e metatarsômero I aproximadamente tão longo quanto os seguintes reunidos.

Ovipositor projetado cerca de 3,5 $\mathrm{mm}$ além das extremidades elitrais; urotergito aguçado; urosternito com recorte raso em forma de U.

Dimensões (mm): comprimento total, $11,0-8,8$; comprimento do protórax, 1,9-1,6; maior largura do protórax, 2,4-2,1; comprimento do élitro, 8,6-6,8; largura umeral, 4,1-3,4.

Discussão: Distingue-se de $S$. rudis e $S$. armatus pelo pronoto com quatro tubérculos; pela presença de uma pequena carena longitudinal centro-basal entre os dois tubérculos posteriores do pronoto e pelas carenas laterais dos élitros projetadas. Em S. rudis e S. armatus: pronoto com apenas dois tubérculos e sem carena longitudinal centro-basal; carenas laterais dos élitros discretas. Assemelha-se a S. armatus pelo aspecto da placa ventral do ovipositor, com recorte raso em forma de U. Em S. rudis a placa ventral tem a forma de V, com recorte ligeiramente profundo.
Material-tipo. Holótipo fêmea, GUATEMALA. El Progreso: 2829 km N Sn Augustin, IV.1990, J.E.Wappes (USNM). Parátipo: mesmos dados do holótipo (MNRJ).

Etimologia. Espécie dedicada a J. E. Wappes (Bulverde, Texas)

\section{Sympleurotis albofasciatus sp. nov.}

(Fig. 4)

Descrição. Fêmea. Tegumento predominantemente castanho-escuro, exceto as pernas e abdômen com tegumento castanho-avermelhado. Densa pubescência decumbente branca reveste as antenas, os fêmures, as tíbias, a metade basal dos tarsômeros I e II, a superfície ventral do corpo e, nos élitros, a base até os tubérculos centro-basais, uma faixa transversal, ligeiramente curva, de contorno irregular, no meio e uma mancha circular, de contorno irregular, que ocupa o quarto apical; o restante dos élitros, a cabeça e o protórax com manchas de pubescência caramelo, mescladas com máculas de pubescência amarela.

Lobos oculares inferiores com, aproximadamente, o mesmo comprimento das genas; lobos superiores tão distantes entre si quanto a largura de um lobo. Antenas ultrapassam oa ápices elitrais a partir da base do antenômero VIII; escapo com o mesmo comprimento do antenômero IV; antenômeros III-X gradualmente decrescentes em comprimento; XI tão longo quanto o X; III-VI ligeiramente intumescidos no ápice.

Protórax com pontuação mais evidente na margem posterior; pronoto com quatro tubérculos rombos pouco desenvolvidos, os dois anteriores próximos e os dois posteriores afastados entre si; pequeno tubérculo centro-basal manifesto. Escutelo com triângulo central de pubescência esbranquiçada, que não atinge o ápice. Élitros com pontos granulados mais concentrados no quarto basal; região centrobasal elevada; carenas laterais apenas indicadas; ápices transversalmente truncados e com pequena projeção espiniforme no ângulos externo.

Fêmures pedunculados e clavados, os metafêmures com o pedúnculo longo e a clava discreta, pouco robusta. Mesotarsômero I tão longo quanto os seguintes reunidos; metatarsômero I mais longo que os seguintes reunidos.

Ovipositor longo, projetado cerca de $6,5 \mathrm{~mm}$ além das extremidades elitrais. Urotergito bastante afilado, urosternito com recorte estreito e profundo.

Dimensões (mm): comprimento total, 13,7; comprimento do protórax, 2,2; maior largura do protórax, 3,1; comprimento do élitro, 10,4; largura umeral, 4,8.

Discussão: Distingue-se das demais espécies de Sympleurotis pelo comprimento dos lobos oculares inferiores 
igual ao das genas; pelos lobos superiores tão distantes entre si quanto a largura de um lobo; pelo metatarsômero I mais longo que os seguintes reunidos; pelo ovipositor bastante longo, projetado cerca de $6,5 \mathrm{~mm}$ além das extremidades elitrais e pela placa ventral do ovipositor com recorte estreito e profundo. Nas demais espécies: lobos oculares inferiores com o comprimento menor que o das genas; lobos superiores tão distantes entre si quanto o dobro da largura de um lobo; metatarsômero I, no máximo, tão longo quanto os seguintes reunidos; ovipositor projetado, no máximo, cerca de $5,0 \mathrm{~mm}$ além das extremidades elitrais; em $S$. armatus e $S$. wappesi $\mathbf{s p .}$ nov. a placa ventral do ovipositor apresenta um recorte raso em forma de $\mathrm{U}$ e em $S$. rudis a placa ventral tem a forma de V, com recorte ligeiramente profundo.

Material-tipo. Holótipo fêmea, MÉXICO. Oaxaca: Hwy. 131, 178 km S Oaxaca, V.1971, J.M.Campbell \& D.E.Bright (MNRJ).

Etimologia. Latim, albus $=$ branco e fascia $=$ faixa. Alusivo à faixa transversal branca no meio dos élitros.

\section{REFERÊNCIAS}

Bates, H. W. 1881. Biologia Centrali-Americana, Insecta, Coleoptera, London, 5: 153-224, prs. 12-15.

Chemsak, J. A. \& Linsley, E. G. 1970. Additional designations of lectotypes of neotropical Cerambycidae in the collections of the British Museum (Natural History) (Coleoptera). Journal of the Kansas Entomological Society, 43: 404-417.

Chemsak, J. A. \& Linsley, E. G. \& Noguera, F. A. 1992. Listados faunísticos de México. II. Los Cerambycidae y Disteniidae de Norteamérica, Centroamérica y las Indias Occidentales (Coleoptera). México, D. F., Univ. Nac. Autón. México, 204 pp.

Gahan, C. J. 1892. Additions to the Longicornia of Mexico and Central America, with notes on some previously-recorded species. The Transactions of the Entomological Society of London 1892 : 255-274, 1 pr.

Lameere, A. A. 1883. Liste des cérambycides, décrits postérieurement au catalogue de Munich. Annales de la Société Entomologique de Belgique, Bruxelles, 26: 1-78.

Monné, M. A. 1995. Catalogue of the Cerambycidae (Coleoptera) of the Western Hemisphere. Part XIX. Subfamily Lamiinae: Tribes Elytracanthini, Cyrtinini, Colobotheini, Tetraopini, and Saperdini. S. Paulo, Sociedade Brasileira de Entomologia, 94 pp.

Noguera, F. A. \& Chemsak, J. A. 1996. Cerambycidae (Coleoptera) (381-409): In: Biodiversidad taxonomía, y biogeografía de artrópodos de México: Hacia una síntesis de su conocimiento. México, D. F., Universidad Nacional Autónoma de México. 